\title{
Psychosocial Predictors of Self-Efficacy Related to Self-Reported Adherence in Older Chronic Patients Dealing with Hypertension: A European Study
}

This article was published in the following Dove Press journal:

Patient Preference and Adherence

\author{
Francesco Zanatta ${ }^{\prime}$ \\ Ekaterina Nissanoval \\ Natalia Świątoniowska- \\ Lonc (iD) ${ }^{2}$ \\ Antonia Pierobon (D) \\ Giovanna Callegari ${ }^{3}$ \\ Francesca Olmetti ${ }^{4}$ \\ Guido Felicetti ${ }^{5}$ \\ Piotr Karniej $\mathbb{D}^{2}$ \\ Jacek Polański ${ }^{6}$ \\ Anna Giardini ${ }^{7}$ \\ Beata Jankowska-Polańska ${ }^{2}$ \\ 'Psychology Unit of Montescano Institute, \\ Istituti Clinici Scientifici Maugeri IRCCS, \\ Montescano (PV), Italy; ${ }^{2}$ Department of \\ Clinical Nursing, Faculty of Health Science, \\ Wroclaw Medical University, Wroclaw, \\ Poland; ${ }^{3}$ Respiratory Rehabilitation Unit of \\ Montescano Institute, Istituti Clinici \\ Scientifici Maugeri IRCCS, Montescano (PV), \\ Italy; ${ }^{4}$ Cardiological Rehabilitation Unit of \\ Montescano Institute, Istituti Clinici \\ Scientifici Maugeri IRCCS, Montescano (PV), \\ Italy; ${ }^{5}$ Neuromotor Rehabilitation Unit of \\ Montescano Institute, Istituti Clinici \\ Scientifici Maugeri IRCCS, Montescano (PV), \\ Italy; ${ }^{6}$ Department of Internal Diseases, \\ Occupational Medicine, Hypertension and \\ Clinical Oncology, Wroclaw Medical \\ University, Wroclaw, Poland; ${ }^{7}$ Information \\ Technology Department, Istituti Clinici \\ Scientifici Maugeri IRCCS, Pavia, Italy
}

Correspondence: Antonia Pierobon Istituti Clinici Scientifici Maugeri IRCCS, Via S. Maugeri, 4, Pavia 27100, Italy

Tel +39385247255

Fax +39385 61386

Email antonia.pierobon@icsmaugeri.it
Purpose: Non-adherence to clinical prescriptions is widely recognized as the most common cause of uncontrolled hypertension, contributing to develop acute and chronic cardiovascular diseases. Specifically, patients' unintentional non-adherence is related to psychosocial factors as beliefs about medications, perceived physician's communication effectiveness and medication-specific social support. The aim of this study was to observe the impact of these factors on self-efficacy in relation to pharmacological and non-pharmacological self-reported adherence among older chronic patients with hypertension.

Patients and Methods: This research had a cross-sectional, observational and multicentre study design. Italian inpatients under rehabilitation, and Polish inpatients/outpatients were recruited. Following a cognitive screening, socio-demographic and clinical characteristics were obtained. Data on clinical and behavioral adherence (i.e., pharmacological adherence, adherence to refill medicines, intentional non-adherence) and psychosocial factors related to treatment adherence (i.e., beliefs about medicines, physician's communication skills, medication-specific social support, psychological antecedents and self-efficacy) were collected with self-report questionnaires.

Results: A total of 458 patients were recruited. Fischer's LSD post hoc test revealed significant differences between Italian and Polish samples in all measures $(p<0.001)$. Multiple linear regression analysis showed low self-reported intentional non-adherence $(\beta$ $=-.02, \mathrm{p}=0.031)$, high self-reported adherence to refill medications $(\beta=-.05, \mathrm{p}=0.017)$, high levels of perceived physician's communication effectiveness $(\beta=0.11, p<0.001)$, positive beliefs about medications $(\beta=0.13, \mathrm{p}<0.001)$, and high perceived medication-specific social support $(\beta=0.05, \mathrm{p}<0.001)$ to predict significantly high patients' self-efficacy in relation to pharmacological and non-pharmacological self-reported adherence.

Conclusion: The observed psychosocial and behavioral factors revealed to positively impact on self-efficacy in relation to treatment adherence among older chronic patients dealing with hypertension. In a prevention framework, future studies and clinical practice may consider these factors in order to improve assessment and intervention on adherence in this population.

Keywords: self-reported adherence, hypertension, chronicity, self-efficacy, older patients, psychosocial

\section{Introduction}

Hypertension is responsible for approximately half of all the cardiovascular events, making it the most important risk factor for cardiovascular diseases such as haemorrhagic stroke, ischaemic stroke, myocardial infarction, peripheral artery 
disease, and heart failure. ${ }^{1}$ Moreover, evidence emerged linking high levels of blood pressure with an increased risk of developing atrial fibrillation, as well as cognitive decline and dementia. ${ }^{2-4}$ The overall prevalence of hypertension was estimated to be over 150 million in central and Eastern Europe, becoming progressively more common among people aged more than 60 years with a prevalence of $60 \%{ }^{5}$ Although effective medications to control hypertension exist, it was shown that nonadherence toward medication is one of the common causes of uncontrolled hypertension, resulting in failure to curb the condition. ${ }^{6,7} \mathrm{WHO}^{8}$ defines adherence to long-term therapy as the extent to which a person's behaviour taking medication, following a diet, and/or executing lifestyle changes - corresponds with the agreed recommendations from a provider, classifying the improvement of pharmacological and non-pharmacological adherence as a key factor for the successful management of major chronic diseases. ${ }^{9}$

Non-adherence can be often classified as intentional or unintentional according to the patient's perspective. ${ }^{10}$ Recent studies indicated that unintentional non-adherence is significantly affected by beliefs about illness and medication or self-efficacy and emotional state. ${ }^{11,12}$ Further studies in patients with chronic diseases revealed unintentional non-adherence to be predicted by beliefs and concerns about medicines. ${ }^{13-15}$ Moreover, there is evidence demonstrating the importance of a patient-physician therapeutic relationship contributing to therapy effectiveness. For instance, lack of cooperation with the patient becomes one of the most important factors leading to ineffectiveness of therapy. ${ }^{16}$ In addition, the Accreditation Council for Graduate Medical Education (ACGME) identified communication skills as 1 of the 6 core competencies of physicians and provided a framework for measuring the development of these skills. ${ }^{17}$ Indeed, effective communication and a patient-centered approach are now the basis for high-quality care. The problem of satisfaction of communication as an element helping to achieve the effectiveness of therapy is the subject of research primarily in the US, while in Europe our knowledge in this area is still limited. ${ }^{18,19}$ Furthermore, higher social support was found to positively affect treatment and adherence, as well as to be strongly associated to higher levels of self-efficacy among hypertensive patients. $^{20,21}$ Above all, self-efficacy was supported as one of the key factors impacting on treatment adherence among chronic patients. ${ }^{22}$
Although measures to improve adherence are widely acknowledged to be a primary intervention, as reported in literature, most of the tools assessing adherence and the intervention aimed to strengthen it, mainly focus on drug assumption and not on behavioral prescriptions. ${ }^{23,24}$ Thus, the primary aim of the current research is to identify which psychosocial and behavioral factors (i.e., refill medications adherence, intentional non-adherence, beliefs about medication, perceived physician's communication skills, and perceived medication-specific social support) may predict self-efficacy in relation to pharmacological and nonpharmacological adherence among older chronic patients with hypertension. In this context, self-efficacy specifically refers to patient's ability to follow pharmacological prescriptions and non-pharmacological recommendations. Secondarily, to observe and compare psychological and behavioral characteristics of the sample.

\section{Patients and Methods}

\section{Study Design, Sample and Procedures}

The current research has a cross-sectional, observational, and multicentre study design. Two institutions were involved: Istituti Clinici Scientifici Maugeri in Montescano (Italy) and the Department of Clinical Nursing of Medical University of Wroclaw (Poland). Older ( $\geq 65$-years-old) Italian inpatients under neuromotor, cardiac and pulmonary rehabilitation, Polish inpatients, and Polish outpatients were recruited. Inclusion criteria included a diagnosis of hypertension under regular treatment with at least 1 antihypertensive drug for minimum 6 months and at least 1 chronic disease (e.g., Chronic Obstructive Pulmonary Disease, asthma, chronic renal disease, ischemic heart disease, chronic heart failure, diabetes, osteoporosis and cerebral vasculopathy). Concomitant chronic diseases were evaluated according to the Cumulative Illness Rating Scale (CIRS). ${ }^{25}$

Exclusion criteria were: severe clinical conditions (i.e., Chronic heart failure NYHA-IV, ischemic heart disease CCS-IV, neoplasmatic disease, acute respiratory disease), no Italian or Polish education, severe visuo-perceptive and language deficits, low subjective motivation/interest or refusal to undergo the evaluation, severe psychiatric disorders (at medical evaluation), severe cognitive deterioration (Mini-Mental State Examination [MMSE] score $\leq 18.3$ ), and no concomitant chronic disease.

Participants' recruitment was conducted from 1 May 2019 to 31 July 2019. A panel consisting of internal 
medicine physicians and nurses conducted preliminary patients' selection by performing a comprehensive physical examination and, following the European Society of Cardiology (ESC) guidelines, ${ }^{1}$ at least 2 blood pressure measurements to diagnose hypertension.

All enrolled patients then provided socio-demographic (i. e., age, gender, educational level, marital status) and clinical data (i.e., blood pressure, presence of specific disease conditions, total number of medical hypertension prescriptions, duration of hypertension and other medical conditions), and consecutively underwent cognitive screening (performed by a researcher) and psychosocial self-report assessment. Patients independently responded to questions referring to information from the last 4 weeks. During instruments completion, patients were supported, in case of necessity, by a researcher throughout the testing period (30' each session).

To ensure consistency in data collection process across patients and settings, the entire research group (Italian and Polish) followed the above-described procedures consistently.

\section{Ethical Consideration}

The participation to the present research was on a voluntary basis and any form of reimbursement was provided. Patients signed an informed consent for data collection and treatment. The study was approved by institutional Review Board and Central Ethics Committee of the ICS Maugeri (CEC) and Polish consent of the bioethics commission (KB) (approval number: Italian CEC N.2304/2019 and Polish KB 265/2019). The study was performed in accordance with the Helsinki Declaration and the principles of good clinical practice, with respect for the rights and dignity of participants.

\section{Measures}

Following the assessment of the cognitive functioning aimed to identify the eligible patients, 7 self-report questionnaires evaluating pharmacological and non-pharmacological adherence, and psychosocial characteristics of the patients to be considered as possible determinants of non-adherence were administered (Table 1).

\section{Cognitive Functioning}

The MMSE was administered to evaluate the cognitive deterioration. MMSE is a widely used screening test for dementia, whose advantages include speed of administration and simplicity of result interpretation. ${ }^{26,27}$ The reliability of MMSE was investigated in several studies and
Table I Measures for Data Collection with Related Construct and Scores Interpretation

\begin{tabular}{|c|c|c|}
\hline Measures & Construct & $\begin{array}{l}\text { Scores Interpretation } \\
(\nearrow \text { High, } \searrow \text { Low) }\end{array}$ \\
\hline MGLS & $\begin{array}{l}\text { Pharmacological } \\
\text { adherence }\end{array}$ & $\begin{array}{l}\nearrow \text { Scores } \nearrow \\
\text { Pharmacological adherence }\end{array}$ \\
\hline ARMS & $\begin{array}{l}\text { Adherence to refill } \\
\text { medicines }\end{array}$ & $\begin{array}{l}\nearrow \text { Scores } \searrow \text { Adherence } \\
\text { to refill medicines }\end{array}$ \\
\hline INAS & $\begin{array}{l}\text { Intentional non- } \\
\text { adherence }\end{array}$ & $\begin{array}{l}\nearrow \text { Scores } \nearrow \text { Intentional } \\
\text { non-adherence }\end{array}$ \\
\hline ASonA & $\begin{array}{l}\text { Antecedents (cognitive, } \\
\text { social, emotional and } \\
\text { behavioral factors) and } \\
\text { self-efficacy related to } \\
\text { adherence }\end{array}$ & $\begin{array}{l}\nearrow \text { Scores } \\
\nearrow \text { Higher cognitive, social } \\
\text { and behavioral abilities } \\
\text { and self-efficacy in } \\
\text { adherence management }\end{array}$ \\
\hline ASonA-SE & $\begin{array}{l}\text { Self-efficacy related to } \\
\text { clinical (pharmacological } \\
\text { and non-pharmacological) } \\
\text { adherence }\end{array}$ & $\begin{array}{l}\nearrow \text { Scores } \\
\nearrow \text { Higher self-efficacy } \\
\text { related to clinical } \\
\text { adherence }\end{array}$ \\
\hline BMQ-I0 & $\begin{array}{l}\text { Beliefs (concerns and } \\
\text { necessity) about medicines }\end{array}$ & $\begin{array}{l}\nearrow \text { Scores } \nearrow \text { Positive } \\
\text { beliefs about medicines }\end{array}$ \\
\hline CAT & $\begin{array}{l}\text { Perceived physician's } \\
\text { communication skills }\end{array}$ & $\begin{array}{l}\nearrow \text { Scores } \nearrow \text { Doctor/ } \\
\text { patient communication }\end{array}$ \\
\hline MSPSS & $\begin{array}{l}\text { Perceived medication- } \\
\text { specific social support }\end{array}$ & $\begin{array}{l}\nearrow \text { Scores } \nearrow \text { Perceived } \\
\text { social support related to } \\
\text { medical adherence }\end{array}$ \\
\hline
\end{tabular}

Abbreviations: MGLS, Morisky Green Levine Scale; ARMS, Adherence to Refills and Medications Scale; INAS, Intentional Non-Adherence Scale; ASonA, Antecedents and Self-efficacy on Adherence Schedule (ASonA-SE, Self-efficacy subscale); BMQ-10, Beliefs about Medicines Questionnaire; CAT, Communication Assessment Tool; MSPSS, Multidimensional Scale of Perceived Social Support.

Folstein reported that the test-retest reliability was $>0.89$, and inter-rater reliability $>0.82 .^{26}$

\section{Self-Reported Adherence}

Adherence was evaluated with the following self-report measures:

- The 4-item MGL Adherence Scale for pharmacological adherence (MGLS) which is designed to measure medication adherence behavior and barriers such as forgetfulness, carelessness, adverse effects, and efficacy. Its psychometric properties, concurrent and predictive validity were examined in a high blood pressure population and provided good reliability scores $(\alpha=0.61) ;^{28}$

- The Adherence to Refills and Medications Scale (ARMS) to determine adherence to refill 
medicines. ${ }^{29,30}$ In this 12-item measure, scores are obtained on a 4-point Likert scale $(1=$ none of the time, 4=all the time). Psychometric properties of the ARMS were evaluated among chronic patients and showed high internal consistency $(\alpha=0.81)$ and significant correlations with the 4-item MGLS (Spearman's $\mathrm{rho}=-0.65, \mathrm{p}<0.01){ }^{29} \quad$ Moreover, a psychometric evaluation of the Polish version was conducted among hypertensive patients providing satisfactory scores as regards internal consistency $(\alpha=0.95) ;^{30}$

- The Intentional Non-Adherence Scale (INAS) to identify intentional non-adherence. ${ }^{10}$ It is a 22-item scale scored on a 5-point Likert scale (1=strongly disagree, $5=$ strongly agree) and divided into 2 subscales exploring the reluctance to take medicine as it reminds one's illness (Resisting Illness Subscale [RI]) and the desire to omit or reduce treatment (Testing Treatment Subscale [TT]). INAS development and validation was conducted in different clinical groups, including hypertensive patients, showing good reliability and high levels of internal consistency for both subscales (RI, $\alpha=0.95$; TT, $\alpha=0.97$ ); ${ }^{10}$

- The Antecedents and Self-efficacy on Adherence Schedule (ASonA) belongs to a wider group of selfreport schedule aimed to evaluate cognitive, behavioral, and emotional determinants of pharmacological and non-pharmacological adherence. ${ }^{24}$ It is a 21 -item schedule scored on a 5 -point Likert scale $(0=$ not at all, 4=very much). The schedule comprises 3 subscales: Antecedents (ASonA-A), which include health condition and health-related limitations acceptance, social support, and knowledge about health condition; Selfefficacy (ASonA-SE), exploring patients' self-care strategies, and patients' ability to adhere to medication assumption and to non-pharmacological recommendations (i.e., physical activity, diet, alcohol consumption, and smoking avoidance); and Affectivity (ASonA-Aff) which measures patients' emotional aspects in relation to the health condition. In previous studies, similar schedules, belonging to the schedules group of ASonA, revealed to be sensible instruments showing strong correlations between antecedents and selfefficacy in relation to adherence. Specifically, it was shown that disease limitations acceptance positively correlated to patient's ability to follow pharmacological and non-pharmacological recommendations and disease acceptance negatively correlated to anxiety and depression. $^{24,31}$ A language adaptation was conducted for the purpose of the current study. Italian and Polish versions were administered (as English translation is provided as supplemental digital content, Italian and Polish versions can be requested from the authors).

\section{Psychosocial Characteristics Related to Clinical Adherence}

Psychosocial factors in relation to pharmacological and non-pharmacological adherence were evaluated with:

The Beliefs about Medicines Questionnaire (BMQ) ${ }^{32}$ is a questionnaire scored on a 5-point Likert scale identifying general attitudes and beliefs toward medicines, the necessity of, and the level of concern about, the medication the patient is currently taking ( $1=$ strongly agree, $5=$ strongly disagree). Specifically, the Italian and Polish validated 10item versions were administered. ${ }^{33,34}$ Both validations were conducted including cardiovascular patients. The Italian version showed overall good reliability scores for Necessity subscale $(\alpha=0.78)$ and for Concerns subscale $(\alpha=0.72)$. Similarly, the Polish adaptation provided satisfactory scores for internal consistency (Cronbach's $\alpha$ ranging from 0.64 to 0.82 );

The Communication Assessment Tool (CAT) $)^{35,36}$ is a 15-item instrument designed to assess patient's view of physician communication effectiveness. Scores were obtained on a 5 -point rating scale ( $1=$ poor, $5=$ excellent). Its original validation provided high overall reliability scores $(\alpha=0.96) ;^{35}$

The Multidimensional Scale of Perceived Social Support (MSPSS) ${ }^{37,38}$ evaluates, using 12 items, the patient's perspective of received medication-specific social support from family, friends, and significant others. Scores are obtained on a 7-point Likert scale (1=strongly disagree, $7=$ strongly agree). The MSPSS validation provided high levels of internal reliability for the total scale $(\alpha=0.88)$, as well as for each subscale: for Friends, Family and Significant Other subscale the obtained Cronbach's $\alpha$ scores were $0.85,0.87$, and 0.91, respectively. ${ }^{37}$

\section{Statistical Analyses}

Descriptive and inferential statistics were performed with the support of $\mathrm{R}$ software (3.6.1 version). ${ }^{39}$ First, means on sample characteristics including age, gender, marital status, weight, height, systolic (SBP) and diastolic (DBP) blood pressure, number of comorbidities, number of hypertension drugs used, and diagnosis of diabetes, and on reported scores 
in all the administered scales were calculated distinguishing 3 subgroups, namely Italian inpatients under rehabilitation, Polish inpatients, and Polish outpatients. Of these, comparisons with one-way ANOVA and chi-squared test were conducted. Fischer's LSD test was used as post hoc procedure. Correlations between quantitative variables (psychosocial and behavioral factors) were assessed with Pearson's correlation coefficient. Accordingly, to the aim of this study, multivariate analysis of simultaneous impact of demographic, psychosocial and behavioral predictors (age, gender, adherence to refills medicines, perceived physician's communication skills, beliefs about medications, and medicationspecific social support) on patients' self-efficacy in relation to clinical adherence (dependent variable) was made by the means of linear regression. Statistical significance was set at $\mathrm{p}<0.05$.

\section{Results}

Four hundred seventy-one patients were screened for eligibility. Of these, only 13 were excluded due to cognitive deterioration and/or linguistic deficits. Four hundred fiftyeight patients met all inclusion criteria. The sample included
63 Italian inpatients undergoing rehabilitation, 130 Polish inpatients, and 265 Polish outpatients. Socio-demographic and clinical characteristics are presented in Table 2. Significant differences emerged in age, gender, weight, SBP, DBP, and number of chronic comorbidities $(\mathrm{p}<0.01)$.

Mean scores comparisons of the tests, among and between the groups, were all significant (ANOVA, $p<0.001)$. In addition, Fischer's LSD post hoc test highlighted that Italian inpatients (A) self-reported higher scores in pharmacological adherence (MGLS), in all psychosocial factors (BMQ-10, CAT, MSPSS), in self-efficacy (ASonA$\mathrm{SE}$ ), and lower scores in intentional non-adherence (INAS), and adherence to refill medications (ARMS) than Polish inpatient (B) and/or outpatients (C) (Table 3).

In Table 4, Pearson's coefficients are reported. Accordingly to the focus of the study, patients' self-efficacy (ASonA-SE) was positively correlated to beliefs about medicines (BMQ-10, $r=0.463, p<0.001$ ), to patient's perception of physicians' communication effectiveness (CAT, $r=0.509$, $\mathrm{p}<0.001$ ), and to perceived medication-specific social support (MSPSS, $\mathrm{r}=0.398, \mathrm{p}<0.001$ ), whereas it was negatively correlated to self-reported intentional non-adherence (INAS, $\mathrm{r}=$

Table 2 Descriptive Results of Socio-Demographic and Clinical Characteristics of the Sample

\begin{tabular}{|c|c|c|c|c|c|c|}
\hline & $\begin{array}{l}\text { Italian } \\
\text { Inpatients } \\
\text { Under Rehab } \\
(A) \\
(n=63)\end{array}$ & $\begin{array}{l}\text { Polish Inpatients } \\
(B) \\
(n=\mid 30)\end{array}$ & $\begin{array}{l}\text { Polish Outpatients } \\
(C) \\
(n=265)\end{array}$ & $p^{*}$ & $\begin{array}{l}\text { Post } \\
\text { Hoc }\end{array}$ & $\begin{array}{l}\text { Total } \\
(n=458)\end{array}$ \\
\hline \multicolumn{7}{|l|}{ Descriptive (M $\pm S D)$} \\
\hline Age & $76.1 \pm 6.3$ & $71.3 \pm 10.4$ & $72.1 \pm 6.1$ & $<0.001$ & $A>C, B$ & $72.4 \pm 7.8$ \\
\hline Weight (kg) & $74.7 \pm 15.6$ & $81.7 \pm \mid 4.3$ & $82.7 \pm 15.5$ & 0.001 & $C, B>A$ & $81.3 \pm 15.4$ \\
\hline Height (m) & $167.2 \pm 9.5$ & $165.1 \pm 12.5$ & $171.5 \pm 110.6$ & 0.762 & & $169.1 \pm 84.5$ \\
\hline $\mathrm{SBP}(\mathrm{mmHg})$ & $106.2 \pm 28.5$ & $|45| \pm 58.7$. & $138.2 \pm \mid 4.4$ & $<0.001$ & $B, C>A$ & $136.9 \pm 36.6$ \\
\hline $\mathrm{DBP}(\mathrm{mmHg})$ & $88.6 \pm 25.3$ & $82.1 \pm 7.2$ & $8 I .1 \pm 8.2$ & $<0.001$ & $A>B, C$ & $82.2 \pm 11.2$ \\
\hline n. of chronic comorbidities & $1.57 \pm 0.78$ & $2.05 \pm 1.03$ & $1.7 \pm 0.79$ & $<0.001$ & $\mathrm{~B}>\mathrm{C}, \mathrm{A}$ & $1.78 \pm 0.88$ \\
\hline n. of hypertension drugs used & $\mathrm{I} .84 \pm 0.83$ & $2.07 \pm 1.11$ & $2.09 \pm 0.97$ & 0.205 & & $1.78 \pm 0.88$ \\
\hline \multicolumn{7}{|l|}{ Frequencies, n (\%) } \\
\hline Gender & & & & 0.007 & & \\
\hline Male & $36(57.1)$ & 47 (35.9) & $98(36.7)$ & & & I8I (39.3) \\
\hline Female & $27(42.9)$ & $84(64.1)$ & $169(63.3)$ & & & $280(60.7)$ \\
\hline Marital status & & & & 0.104 & & \\
\hline Married, Living with a partner & $34(54.0)$ & $90(68.7)$ & $161(60.3)$ & & & $285(6 \mid .8)$ \\
\hline Single, Divorced & $29(46.0)$ & $4 \mid(3 \mid .3)$ & $106(39.7)$ & & & $176(38.2)$ \\
\hline Diabetes & & & & 0.077 & & \\
\hline Diabetes & $24(38.1)$ & $62(47.3)$ & $95(35.6)$ & & & I8I (39.3) \\
\hline No diabetes & 39 (61.9) & $69(52.7)$ & $172(64.4)$ & & & $280(60.7)$ \\
\hline
\end{tabular}

Notes: *p-value from ANOVA for continuous variable and from $\mathrm{X}^{2}$ test for categorial variables. Fischer's LSD was used as post hoc procedure.

Abbreviations: SBP, systolic blood pressure; DBP, diastolic blood pressure. 
Table 3 Mean Scores of the Sample and Comparisons Among and Between Subgroups

\begin{tabular}{|c|c|c|c|c|c|c|}
\hline $\begin{array}{l}\text { Measure } \\
\text { (Range) }\end{array}$ & 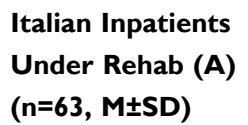 & $\begin{array}{l}\text { Polish } \\
\text { Inpatients (B) } \\
(n=130, M \pm S D)\end{array}$ & $\begin{array}{l}\text { Polish } \\
\text { Outpatients (C) } \\
(n=265, M \pm S D)\end{array}$ & $p^{*}$ & Post Hoc & $\begin{array}{l}\text { Total } \\
(n=458, M \pm S D)\end{array}$ \\
\hline $\begin{array}{l}\text { MGLS } \\
(0-4)\end{array}$ & $3.5 \pm 0.8$ & $1.8 \pm 1.3$ & $2.2 \pm 1.4$ & $<0.001$ & $A>C>B$ & $2.3 \pm 1.4$ \\
\hline $\begin{array}{l}\text { ARMS } \\
(14-56)\end{array}$ & $18.3 \pm 1.8$ & $27.5 \pm 7.7$ & $31.1 \pm 9.7$ & $<0.001$ & $C>B>A$ & $28.3 \pm 9.5$ \\
\hline $\begin{array}{l}\text { INAS } \\
(22-110)\end{array}$ & $24.1 \pm 7.9$ & $43.5 \pm 20.8$ & $49.6 \pm 19.5$ & $<0.001$ & $C>B>A$ & $44.4 \pm 20.6$ \\
\hline $\begin{array}{l}\text { ASonA } \\
(0-80)\end{array}$ & $60.7 \pm 11.2$ & $45.3 \pm 10.2$ & $46.7 \pm 9.8$ & $<0.001$ & $A>C, B$ & $48.0 \pm 11.3$ \\
\hline $\begin{array}{l}\text { ASonA-SE } \\
(0-24)\end{array}$ & $20.7 \pm 2.4$ & $15.7 \pm 4.7$ & $15.8 \pm 4.5$ & $<0.001$ & $A>C, B$ & $16.5 \pm 4.6$ \\
\hline $\begin{array}{l}\text { BMQ- IO } \\
(I I-55)\end{array}$ & $43.1 \pm 6.2$ & $25.6 \pm 4.9$ & $26.2 \pm 4.9$ & $<0.001$ & $A>C, B$ & $28.3 \pm 7.8$ \\
\hline $\begin{array}{l}\text { CAT } \\
(15-75)\end{array}$ & $63.6 \pm 10.6$ & $50.2 \pm 13.2$ & $52.3 \pm 12.1$ & $<0.001$ & $A>C, B$ & $53.3 \pm 12.9$ \\
\hline $\begin{array}{l}\text { MSPSS } \\
(12-84)\end{array}$ & $68.3 \pm 14.5$ & $59.7 \pm 16.9$ & $58.5 \pm 16.1$ & $<0.001$ & $A>B, C$ & $60.2 \pm 16.5$ \\
\hline
\end{tabular}

Notes: * $p$-value from the analysis of variance (ANOVA). Fischer's LSD test was used as post hoc procedure.

Abbreviations: M, mean; SD, standard deviation; MGLS, Morisky Green Levine Scale; ARMS, Adherence to Refills and Medications Scale; INAS, Intentional Non-Adherence Scale; ASonA, Antecedents and Self-efficacy on Adherence Schedule (ASonA-SE, Self-efficacy subscale); BMQ-I0, Beliefs about Medicines Questionnaire; CAT, Communication Assessment Tool; MSPSS, Multidimensional Scale of Perceived Social Support.

Table 4 Pearson's Correlation Coefficients of All Measures

\begin{tabular}{|c|c|c|c|c|c|c|c|c|}
\hline & BMQ- 10 & CAT & MSPSS & MGLS & INAS & ARMS & ASonA & ASonA-SE \\
\hline BMQ-IO & - & & & & & & & \\
\hline CAT & $0.397^{* *}$ & - & & & & & & \\
\hline MSPSS & $0.268^{* *}$ & $0.353^{* *}$ & - & & & & & \\
\hline MGLS & $0.239 * *$ & 0.03 & $-0.136^{*}$ & - & & & & \\
\hline INAS & $-0.35 I^{* *}$ & $-0.137^{* *}$ & $-0.256^{* *}$ & 0.036 & - & & & \\
\hline ARMS & $-0.397^{* *}$ & $-0.213^{* *}$ & $-0.284 * *$ & $0.458 * *$ & 0.366 ** & - & & \\
\hline ASonA & $0.52 * *$ & $0.566^{* *}$ & $0.46 I^{* *}$ & 0.036 & $-0.232 * *$ & $-0.348 * *$ & - & \\
\hline ASonA-SE & $0.463 * *$ & $0.509 * *$ & $0.398^{* *}$ & -0.005 & $-0.255^{* *}$ & $-0.334 * *$ & $0.805^{* *}$ & - \\
\hline
\end{tabular}

Notes: ${ }^{*} \mathrm{p}<0.01,{ }^{* *} \mathrm{p}<0.001$.

Abbreviations: BMQ-10, Beliefs about Medicines Questionnaire; CAT, Communication Assessment Tool; MSPSS, Multidimensional Scale of Perceived Social Support; MGLS, Morisky Green Levine Scale; INAS, Intentional Non-Adherence Scale; ARMS, Adherence to Refills and Medications Scale; ASonA, Antecedents and Self-efficacy on Adherence Schedule (ASonA-SE, Self-efficacy subscale).

$-0.255, \mathrm{p}<0.001)$ and to self-reported adherence to refill medicines (ARMS, $\mathrm{r}=-0.334, \mathrm{p}<0.001$ ).

The multiple regression analysis indicated that low selfreported intentional non-adherence (INAS, $\beta=-.02$, $\mathrm{p}=0.031)$, high self-reported adherence to refill medications (ARMS, $\beta=-.05, p=0.017$ ), positive beliefs about medications (BMQ-10; $\beta=0.13, p<0.001$ ), positive perception of physicians' communication skills (CAT; $\beta=0.11, \mathrm{p}<0.001$ ), high perceived medication-specific social support (MSPSS; $\beta=0.05, p<0.001$ ) significantly predicted high levels of patients' self-efficacy related to pharmacological and nonpharmacological adherence (Table 5).

\section{Discussion}

To date, research and clinical practice on adherence mainly focused on drug assumption rather than behavioral, 
Table 5 Results from the Multiple Regression Analysis Considering Patients' Self-Efficacy as Dependent Variable (ASonA-SE, $n=458$ )

\begin{tabular}{|l|l|l|l|l|}
\hline $\begin{array}{l}\text { Indipendent } \\
\text { Variables }\end{array}$ & Coefficient & \multicolumn{2}{|l|}{$95 \%$ Cl } & $p$ \\
\hline BMQ-10 & 0.126 & 0.074 & 0.178 & $<0.001$ \\
CAT & 0.114 & 0.085 & 0.144 & $<0.001$ \\
MSPSS & 0.043 & 0.02 & 0.065 & $<0.001$ \\
ARMS & -0.049 & -0.089 & -0.009 & 0.017 \\
INAS & -0.021 & -0.04 & -0.002 & 0.031 \\
Age & -0.042 & -0.098 & 0.014 & 0.14 \\
Gender & 0.346 & -.0342 & 1.034 & 0.323 \\
\hline
\end{tabular}

Abbreviations: ASonA-SE, Antecedents and Self-efficacy on Adherence Schedule - Self-efficacy subscale; BMQ-10, Beliefs about Medicines Questionnaire; CAT, Communication Assessment Tool; MSPSS, Multidimensional Scale of Perceived Social Support; ARMS, Adherence to Refills and Medications Scale; INAS, Intentional Non-Adherence Scale.

cognitive, social, and emotional antecedents. ${ }^{12,23,24}$ The current cross-sectional, observational and multicentre research represented an attempt to identify possible psychosocial and behavioral factors predicting self-efficacy related to pharmacological and non-pharmacological self-reported adherence among older chronic patients dealing with hypertension. In particular, the concept of adherence was considered and evaluated in accordance to patient's perspective rather than to specific direct measurements. Thus, the presented and discussed outcomes are to be considered in a patient reported framework. The study therefore explored the role of patients' adherent behaviors, beliefs about medications, perception of physicians' communication effectiveness, perception of medication-specific social support in relation to perceived self-efficacy on adherence.

Previous research already underlined the importance of patients' health beliefs and self-efficacy in medication adherence management, suggesting their relationships to vary unpredictably across and within countries. ${ }^{40}$ To the best of our knowledge, the current research is the first to investigate and compare self-reported adherence among Italian inpatients undergoing a multidisciplinary rehabilitation intervention, and Polish inpatients and outpatients. Patients' socio-demographic and clinical characteristics were heterogeneous. A significant difference on total sample gender distribution emerged in contrast to previous worldwide surveys showing high blood pressure prevalence to be $2420 \%$ in men and women, respectively. ${ }^{41}$ Moreover, Italian patients were significantly older, and presented higher overall means in DBP. Polish patients reported higher overall scores in weight, and in SBP. Specifically, Polish inpatients showed a higher number of chronic comorbidities. Furthermore, Italian patients showed higher scores in all measured psychosocial and behavioral factors than both subgroups of Polish patients, and more specifically, Polish inpatients revealed higher rates than Polish outpatients' ones.

As to the purpose of the current study, recent researches on hypertensive population reported that intentional non-adherence, self-efficacy, perceived social support, affectivity, and health beliefs were significant determinants and mediators of treatment adherence. ${ }^{6,42-44}$ The current research strengthened this knowledge, showing that more positive beliefs stronger necessity and lower concerns about medicines, and higher perceived medication-specific social support, as well as lower intentional non-adherence and higher adherence to refill medicines, significantly predicted higher patients' self-efficacy in relation to pharmacological and non-pharmacological adherence. These factors may sustain and reinforce the person's motivation and strategic skills, resulting in the empowerment of the patient who increases her/his self-efficacy. To this regard, the Three Factor Model already underlined the pivotal role of motivation and strategies to maintain the adherent behavior. ${ }^{12}$ Further studies are encouraged to better explore this hypothesis.

Another added value of this study is that positive perception of physicians' communication effectiveness was revealed to be an independent factor of higher selfefficacy, too. This finding supports what emerged from previous studies, which considered a physician's communication skills as a potential key factor in improving patients' medication beliefs, self-efficacy, and medication adherence. $^{45,46}$

Further prospective cohort research should be conducted in order to investigate the long-term mediator influence of self-efficacy on the relationship between its determinants and clinical adherence. Moreover, future studies may also investigate whether higher levels of the latter may further lead to positive effects on its determinants, contributing to develop a circular and virtuous model (Figure 1). The implementation of this model may orient future empirical assessment and interventions too, in order to foster chronic and hypertensive patient's selfmanagement and self-care.

This research was conducted considering a wide sample, but some limitations are to be reported: a wide range of chronic comorbidities, 2 different cultures, the 


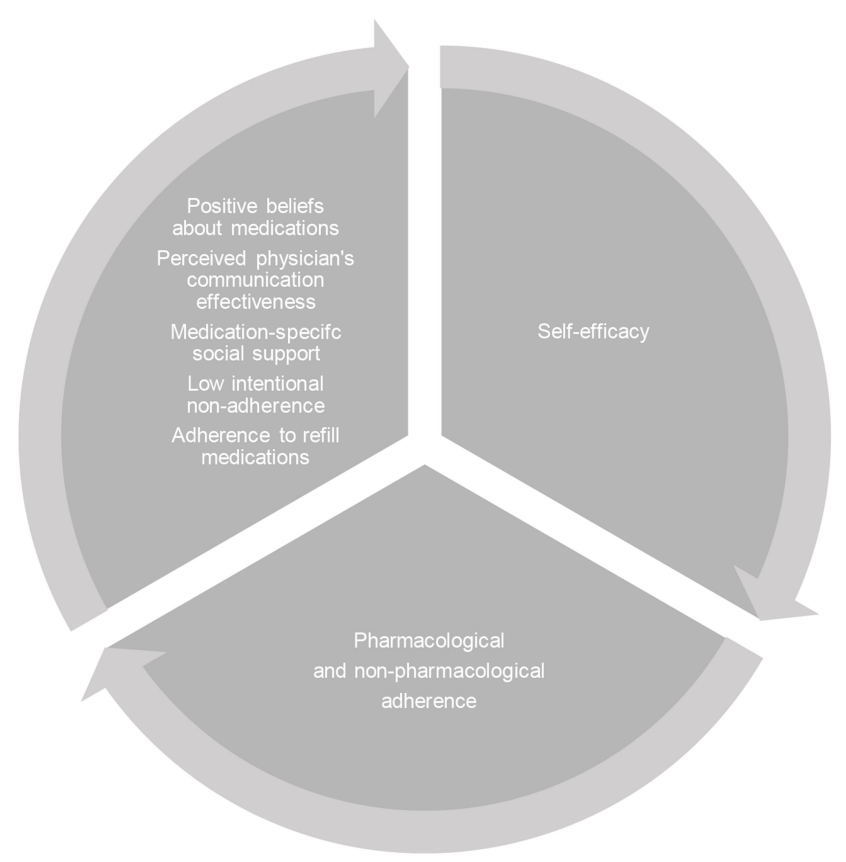

Figure I Model showing possible circular effect of higher levels of psychosocial and behavioral factors, self-efficacy, and clinical adherence.

absence of cognitive impairment and 3 typologies of health care settings were considered. On the other hand, the heterogeneity of the sample may however allow us to generalize the findings on chronic inpatients and outpatients with hypertension. In addition, the absence of cognitive impairment may recommend future interventions to focus on adherence management among chronic and hypertensive patients with a cognitive decline. In fact, studies on this population already showed low adherence to be strongly associated with cognitive and physical barriers, leading drug assumption difficult to be managed regularly. ${ }^{47,48}$ Furthermore, as the current research shows that social support could be a protective factor in adherence management, future studies on patients with cognitive deterioration or dementia may include the role of their caregivers in order to improve these behaviors.

Beliefs about medications, perceived physicians' communication effectiveness, and medication-related social support may be considered as sensible determinants of patients' self-efficacy on adherence. This ultimate outcome should be considered as a contribution to the literature on antecedents of patient reported adherence. This might orient future research and empirical interventions to focus on these factors in order to also improve clinical adherence in psychosocial and behavioral terms.

\section{Conclusion}

The current research represented a first attempt in exploring and comparing the psychosocial and behavioral factors that determine clinical self-reported adherence among Italian and Polish older chronic patients dealing with hypertension. Findings showed positive beliefs about medications, positive perception of physicians' communication skills, high perceived medication-related social support, as well as lower intentional non-adherence and adherence to refill medications to be significant predictors of high patients' self-efficacy influencing adherent behaviors. Adopting a patient reported adherence approach, clinical practice and future research should take into account these factors in order to better clarify and deepen the role of the antecedents of adherence and, thus, to develop empirical assessments and psychosocial and behavioural interventions aimed to improve pharmacological and non-pharmacological adherence in this clinical population.

\section{Funding}

This work was partially supported by the "Ricerca Corrente" funding scheme of the Ministry of Health (Italy), and partly financed by the Medical University of Wroclaw (Poland).

\section{Disclosure}

The authors declare no conflicts of interest regarding this study.

\section{References}

1. Williams B, Mancia G, Spiering W, et al. ESC/ESH guidelines for the management of arterial hypertension: the task force for the management of arterial hypertension of the European Society of Cardiology (ESC) and the European Society of Hypertension (ESH). J Hypertens. 2018;36 (10):1953-2041. doi:10.1097/HJH.0000000000001940

2. Lip GYH, Coca A, Kahan T, et al. Hypertension and cardiac arrhythmias: executive summary of a consensus document from the European Heart Rhythm Association (EHRA) and ESC Council on Hypertension, endorsed by the Heart Rhythm Society (HRS), Asia-Pacific Heart Rhythm Society (APHRS), and Sociedad Latinoamericana de Estimulacion Cardiaca y Electrofiosologica (SOLEACE). Eur Heart J Cardiovasc Pharmacother. 2017;3 (4):235-250. doi:10.1093/ehjcvp/pvx019

3. Gottesman RF, Albert MS, Alonso A, et al. Associations between midlife vascular risk factors and 25-year incident dementia in Atherosclerosis Risk Communities (ARIC) cohort. JAMA Neurol. 2017;74(10):1246-1254. doi:10.1001/jamaneurol.2017.1658

4. Rovio SP, Pahkala K, Nevalainen J, et al. Cardiovascular risk factors from childhood and mildlife cognitive performance: the Young Finns study. J Am Coll Cardiol. 2017;69(18):2279-2289. doi:10.1016/j. jacc.2017.02.060

5. Chow CK, Teo KK, Rangarajan S, et al. PURE Study investigators. Prevalence, awareness, treatment, and control of hypertension in rural and urban communities in high-, middle-, and low-income countries. JAMA. 2013;310(9):959-968. doi:10.1001/jama.2013.184182 
6. Morrison VL, Holmes EAF, Parveen S, et al. Predictors of self-reported adherence to antihypertensive medicines: a multinational, cross-sectional survey. Value Health. 2015;18 (2):206-216. doi:10.1016/j.jval.2014.12.013

7. Abegaz TM, Shehab A, Gebreyohannes EA, Bhagavathula AS, Elnour AA. Nonadherence to antihypertensive drugs: A systematic review and meta-analysis. Medicine. 2017;96(4):e5641. doi:10.1097/ MD.0000000000005641

8. World Health Organization. Adherence to Long-Term Therapies. Evidences for Action. Geneva: World Health Organization Press; 2003.

9. World Health Organization. Noncommunicable Diseases and Mental Health. Global Action Plan for the Prevention and Control of NCDs 20132020. Geneva: World Health Organization Press; 2013.

10. Weinman J, Graham S, Canfield M, et al. The Intentional Non-Adherence Scale (INAS): initial development and validation. J Psychosom Res. 2018;115:110-116. doi:10.1016/j.jpsychores.2018.10.010

11. Horne R, Chapman SC, Parham R, Freemantle N, Forbes A, Cooper V. Understanding patients' adherence-related beliefs about medicines prescribed for long-term conditions: a meta-analytic review of the necessity-concerns framework. PLoS One. 2013;8 (12):e80633. doi:10.1371/journal.pone. 0080633

12. Martin LR, Dimatteo MR. The Oxford Handbook of Health Communication, Behaviour Change, and Treatment Adherence. New York: Oxford University Press; 2014.

13. Vrijens B, De Geest S, Hughes DA, et al. A new taxonomy for describing and defining adherence to medications. $\mathrm{Br} J$ Clin Pharmacol. 2012;73(5):691-705. doi:10.1111/j.13652125.2012.04167.x

14. Ruppar TM, Dobbels F, De Geest S. Medication beliefs and antihypertensive adherence among older adults: a pilot study. Geriatr Nurs. 2012;33(2):89-95. doi:10.1016/j.gerinurse.2012.01.006

15. Dillon P, Phillips LA, Gallagher P, Smith SM, Stewart D, Cousins G. Assessing the multidimensional relationship between medication beliefs and adherence in older adults with hypertension using polynomial regression. Ann Behav Med. 2018;52(2):146-156. doi: $10.1093 / \mathrm{abm} / \mathrm{kax} 016$

16. Vahdat S, Hamzehgardeshi L, Hessam S, Hamzehgardeshi Z. Patient involvement in health care decision making: a review. Iran Red Crescent Med J. 2014;16(1):e12454. doi:10.5812/ircmj.12454

17. Batalden P, Leach D, Swing S, Dreyfus H, Dreyfus S. General competencies and accreditation in graduate medical education. Health Aff. 2002;21(5):103-111. doi:10.1377/hlthaff.21.5.103

18. Street RL, Makoul G, Arora NK, Epstein RM. How does communication heal? Pathways linking clinician-patient communication to health outcomes. Patient Educ Couns. 2009;74(3):295-296. doi:10.1016/j.pec.2008.11.015

19. Zolnierek KBH, Dimatteo MR. Physician communication and patient adherence to treatment: a meta-analysis. Med Care. 2009;47 (8):826-828. doi:10.1097/MLR.0b013e31819a5acc

20. Padhy M, Lalnuntluangi R, Chelli K, Padiri RA. Social Support and Adherence among hypertensive patients. AJHM. 2016;1(1):33-40.

21. Turan GB, Aksoy M, Çiftçi B. Effect of social support on the treatment adherence of hypertension patients. J Vasc Nurs. 2019;37 (1):46-51. doi:10.1016/j.jvn.2018.10.005

22. Shahin W, Kennedy GA, Stupans I. The impact of personal and cultural beliefs on medication adherence of patients with chronic illnesses: a systematic review. Patient Prefer Adherence. 2019;13:1019-1035. doi:10.2147/PPA.S212046

23. Nieuwlaat R, Wilezynsky $\mathrm{N}$, Navarro $\mathrm{T}$, et al. Interventions for enhancing medication adherence. Cochrane Database Syst Rev. 2014:CD000111. doi:10.1002/14651858.CD000011.pub4.

24. Pierobon A, Sini Bottelli E, Ranzini L, et al. COPD patients' selfreported adherence, psychosocial factors and mild cognitive impairment in pulmonary rehabilitation. Int J Chron Obstruct Pulmon Dis. 2017;12:2059-2067. doi:10.2147/COPD.S133586
25. Miller MD, Paradis CF, Houck PR, Mazudmar S, Stack JA, Rifai AH. Ratings chronic medical illness burden in geropsychiatric practice and research: application of the cumulative illness rating scale. Psychiatry Res. 1992;41(3):237-248. doi:10.1016/0165-1781(92) 90005-n

26. Folstein MF, Folstein SE, McHugh PR. Mini-mental state: a practical method for grading the cognitive state of patients for the clinician. J Psychiatr Res. 1975;12(3):196-198. doi:10.1016/0022-3956(75) 90026-6

27. Magni E, Binetti G, Bianchetti A, Rozzini R, Trabucchi M. Minimental state examination: a normative study in Italian elderly population. Eur J Neurol. 1996;3(3):198-202. doi:10.1111/j.14681331.1996.tb00423.x

28. Morisky DE, Green LW, Levine DM. Concurrent and predictive validity of a self-reported measure of medication adherence. Med Care. 1986;24(1):67-74. doi:10.1097/00005650-198601000-00007

29. Kripalani S, Risser J, Gatti ME, Jacobson TA. Development and evaluation of the Adherence to Refills and Medications Scale (ARMS) among low-literacy patients with chronic disease. Value Health. 2009;12(1):118-123. doi:10.1111/j.1524-4733.2008.00400.x

30. Lomper K, Chabowski M, Chudiak A, Białoszewski A, Dudek K, Jankowska-Polańska B. Psychometric evaluation of the Polish version of the Adherence to Refills and Medications Scale (ARMS) in adults with hypertension. Patient Prefer Adherence. 2018;12:2661-2670. doi:10.2147/PPA.S185305

31. Pierobon A, Giardini A, Majani G, et al. Into the cognitive constructs related to adherence to treatment in CHD outpatients: the importance of accepting the disease limitations. Monaldi Arch Chest Dise. 2009;72(3):130-138.

32. Horne R, Weinman J. Patients' beliefs about prescribed medicines and their role in adherence to treatment in chronic physical illness. J Psychosom Res. 1999;47(6):555-567. doi:10.1016/s0022-3999(99) 00057-4

33. Argentero P, Torchio E, Tibaldi G, Horne R, Clatworthy J, Munizza C. [The beliefs aboud drug treatment. The Italian version of the BMQ (The Beliefs about Medicines Questionnaire): its validity and applicability]. Epidemiol Psichiatr Soc. 2010;19(1):86-92. [Article in Italian] doi:10.1017/S1121189X00001640

34. Karbownik MS, Jankowska-Polańska B, Horne R, Górski KM, Kowalczyk E, Szemraj J. Adaptation and validation of the polish version of the beliefs about medicines questionnaire among cardiovascular patients and medical students. PLoS One.2020;15:e230131. doi:10.1371/journal.pone. 0230131

35. Makoul G, Krupat E, Chang CH. Measuring Patient views of physicians communication skills development and testing of the communication assessment tool. Patient Educ Couns. 2007;67(3):333-342. doi:10.1016/j.pec.2007.05.005

36. Scala D, Menditto E, Armellino MF, et al. Italian translation and cultural adaptation of the communication assessment tool in an outpatient surgical clinic. BMC Health Serv Res. 2016;16:163. doi:10.1186/s12913-016-1411-9

37. Zimet GD, Powell SS, Farley GK, Werkman S, Berkoff KA. Psychometric characteristics of the Multidimensional Scale of Perceived Social Support. J Pers Assess. 1990;55(34):610-617. doi:10.1080/00223891.1990.9674095

38. Di Fabio A, Palazzeschi L. [Multidimensional Scale of Perceived Social Support (MSPSS): un contributo alla validazione italiana]. Counseling. 2015;8:1-15.[Article in Italian]

39. R Core Team. R: A language and environment for statistical computing. R foundation for statistical computing. Austria; 2019. Available from: https://www.R-project.org/. Accessed August 20, 2020.

40. Al-Noumani H, Wu JR, Barksdale D, Sherwood G, Alkhasawneh E, Knafl G. Health beliefs and medication adherence in patients with hypertension: a systematic review of quantitative studies. Patient Educ Couns. 2019;102(6):1045-1056. doi:10.1016/j.pec.2019.02.022 
41. NCD Risk Factor Collaboration (NCD-RisC). Worldwide trends in blood pressure from 1975 to 2015: a pooled analysis of 1479 population-based measurement studies with 19.1 million participants. Lancet. 2017;389(10064):37-55. doi:10.1016/S01406736(16)31919-5.

42. Maeda U, Shen BJ, Schwarz ER, Farrell KA, Mallon S. Self-efficacy mediates the associations of social support and depression with treatment adherence in heart failure patients. Int $J$ Behav Med. 2013;20(1):88-96. doi:10.1007/s12529-011-9215-0

43. Rajpura J, Nayak R. Medication adherence in a sample of elderly suffering from hypertension: evaluating the influence of illness perceptions, treatment beliefs, and illness burden. J Manag Care Pharm. 2014;20(1):58-65. doi:10.18553/jmcp.2014.20.1.58

44. Nafradi L, Galimberti E, Nakamoto K, Schultz PJ. Intentional and unintentional medication non-adherence in hypertension: the role of health literacy, empowerment and medication beliefs. J Public Health Res. 2016;5(3):762. doi:10.4081/jphr.2016.762
45. Hong SH. Potential for physician communication to build favorable medication beliefs among older adults with hypertension: A cross-sectional survey. PLoS One. 2019;14(1):e0210169. doi:10.1371/journal.pone.0210169

46. Tavakoly Sany SB, Behzhad F, Ferns G, Peyman N. Communication skills training for physicians improves health literacy and medical outcomes among patients with hypertension: a randomized controlled trial. BMC Health Serv Res. 2020;20(1):60. doi:10.1186/s12913-0204901-8

47. Cho MH, Shin DW, Chang SA, et al. Association between cognitive impairment and poor antihypertensive medication adherence in elderly hypertensive patients without dementia. Sci Rep. 2018;8 (1):11688. doi:10.1038/s41598-018-29974-7

48. El-Saifi N, Moyle W, Jones C, Tuffaha H. Medication adherence in older patients with dementia: a systematic literature review. J Pharm Pract. 2018;8(1):322-334. doi:10.1038/s41598-018-29974-7

\section{Publish your work in this journal}

Patient Preference and Adherence is an international, peer-reviewed, open access journal that focusing on the growing importance of patient preference and adherence throughout the therapeutic continuum. Patient satisfaction, acceptability, quality of life, compliance, persistence and their role in developing new therapeutic modalities and compounds to optimize clinical outcomes for existing disease states are major areas of interest for the journal. This journal has been accepted for indexing on PubMed Central. The manuscript management system is completely online and includes a very quick and fair peer-review system, which is all easy to use. Visit http:// www.dovepress.com/testimonials.php to read real quotes from published authors. 